\title{
COMBINED TLR AGONIST AND AEROMONAS ANTIGENS STIMULATION ENHANCE THE IMMUNE-RELATED GENES IN YELLOWTAIL LEUCOCYTES
}

\section{Martha Reyes-Becerril $^{1 \S}$, Felipe Ascencio-Valle ${ }^{1 *}$, Ikuo Hirono ${ }^{2 \star}$, María Ángeles Esteban ${ }^{3 *}$, Carlos Angulo ${ }^{1 *}$}

${ }^{1}$ Centro de Investigaciones Biológicas del Noroeste (CIBNOR), Instituto Politécnico Nacional 195, Playa Palo de Santa Rita Sur, La Paz, B.C.S. 23096, México

${ }^{2}$ Laboratory of Genome Science, Tokyo University of Marine Science and Technology, Konan 4-5-7, Minato-ku, Tokyo, 108-8477, Japan

${ }^{3}$ Fish Innate Immune System Group, Department of Cell Biology and Histology, Faculty of Biology, Campus of International Excellence, Campus Mare Nostrum, University of Murcia, Murcia, Spain.

The purpose of this study was to characterize the TLR21 gene from yellowtail (Seriola lalandi) and its functional activity using TLR agonist stimulation and Aeromonas antigens. Basal TLR21 gene expression was analyzed in several tissues. Subsequently, the gene expression of TLR2 1 and IL-1 $\beta$ and TNF- $\alpha$ cytokines was evaluated in head-kidney leucocytes exposed to TLR agonists (CpGODN2006, LPS and Poly I:C) and then subjected to Aeromonas antigen stimulation. The yellowtail full-length cDNA sequence of SlTLR21 was 3615 bp (980 aa). The sequence showed a high degree of similarity with the counterparts of other fish species and shared the common structural architecture of the TLR family, including LRR domains, one C-terminal LRR region and a TIR domain. Gene expression studies revealed the constitutive expression of TLR2 1 mRNA in all the analyzed tissues, the highest levels being observed in spleen and head-kidney, where they play an important role in the fish immune system. Transcripts of TLR21 and the downstream IL-1 $\beta$ and TNF$\alpha$ cytokine genes were most strongly up-regulated after exposure to the TLR agonists, following Aeromonas antigen stimulation, suggesting they are involved in the immune response. The results indicate that TLR agonists, in combination with Aeromonas antigens in head-kidney leucocytes, synergistically enhance TLR21 and cytokines gene expression in yellowtail.

Keywords: TLR21; Agonist TLR's; Aeromonas antigens; cytokine gene expression; Seriola lalandi

*These authors have contributed equally to this work.

§Corresponding author. Tel.: +52 6121544733.

E-mail address: mreyes04@ cibnor.mx 